\title{
High creatinine clearance in critically ill patients with community-acquired acute infectious meningitis
}

\author{
Alexandre Lautrette ${ }^{1,2^{*}}$, Thuy-Nga Phan ${ }^{1}$, Lemlih Ouchchane ${ }^{2,3}$, Ali AitHssain ${ }^{1}$, Vincent Tixier ${ }^{1}$, \\ Anne-Elisabeth Heng ${ }^{1,2}$ and Bertrand Souweine ${ }^{1,2}$
}

\begin{abstract}
Background: A high dose of anti-infective agents is recommended when treating infectious meningitis. High creatinine clearance $(\mathrm{CrCl})$ may affect the pharmacokinetic / pharmacodynamic relationships of anti-infective drugs eliminated by the kidneys. We recorded the incidence of high $\mathrm{CrCl}$ in intensive care unit (ICU) patients admitted with meningitis and assessed the diagnostic accuracy of two common methods used to identify high $\mathrm{CrCl}$.

Methods: Observational study performed in consecutive patients admitted with community-acquired acute infectious meningitis (defined by $>7$ white blood cells $/ \mathrm{mm}^{3}$ in cerebral spinal fluid) between January 2006 and December 2009 to one medical ICU. During the first 7 days following ICU admission, $\mathrm{CrCl}$ was measured from 24-hr urine samples (24-hr-UV/P creatinine) and estimated according to Cockcroft-Gault formula and the simplified Modification of Diet in Renal Disease (MDRD) equation. High $\mathrm{CrCl}$ was defined as $\mathrm{CrCl}>140 \mathrm{ml} / \mathrm{min} / 1.73 \mathrm{~m}^{2}$ by 24-hr-UV/P creatinine. Diagnostic accuracy was performed with ROC curves analysis.

Results: Thirty two patients were included. High $\mathrm{CrCl}$ was present in 8 patients (25\%) on ICU admission and in 15 patients (47\%) during the first 7 ICU days for a median duration of $3(1-4)$ days. For the Cockcroft-Gault formula, the best threshold to predict high $\mathrm{CrCl}$ was $101 \mathrm{ml} / \mathrm{min} / 1.73 \mathrm{~m}^{2}$ (sensitivity: 0.96, specificity: 0.75, AUC $=0.90 \pm 0.03$ ) with a negative likelihood ratio of 0.06 . For the simplified MDRD equation, the best threshold to predict high $\mathrm{CrCl}$ was $108 \mathrm{ml} / \mathrm{min} / 1.73 \mathrm{~m}^{2}$ (sensitivity: 0.91, specificity: 0.80, AUC $=0.88 \pm 0.03$ ) with a negative likelihood ratio of 0.11 . There was no difference between the estimated methods in the diagnostic accuracy of identifying high $\mathrm{CrCl}$ $(p=0.30)$.
\end{abstract}

Conclusions: High $\mathrm{CrCl}$ is frequently observed in ICU patients admitted with community-acquired acute infectious meningitis. The estimated methods of $\mathrm{CrCl}$ could be used as a screening tool to identify high $\mathrm{CrCl}$.

Keywords: Critically ill, Glomerular filtration rate, High creatinine clearance, Meningitis

\section{Background}

The glomerular filtration rate (GFR) can affect the pharmacokinetic/pharmacodynamic relationships of drugs eliminated by the kidney. The dosages and intervals of administration of these drugs are routinely adjusted in patients with a diminished GFR to achieve effective treatment and to limit drug-induced toxicity. GFR is

\footnotetext{
* Correspondence: alautrette@chu-clermontferrand.fr

'Departments of Intensive Care Unit and Nephrology, University hospital of Clermont-Ferrand, Clermont-Ferrand, France

¿Univ Clermont 1, UFR Médecine, Clermont-Ferrand F-63001, France

Full list of author information is available at the end of the article
}

currently estimated in clinical practice by creatinine clearance $(\mathrm{CrCl}) . \mathrm{CrCl}$ is recommended in most textbooks and guidelines to decide on the dosage of drugs with kidney clearance for patients with renal insufficiency. In most studies $\mathrm{CrCl}$ is measured from 24-hour urine samples (24-hr-UV/P creatinine) or estimated according to Cockcroft-Gault formula and the simplified Modification of Diet in Renal Disease (MDRD) equation [1].

High $\mathrm{CrCl}$ has been reported in groups of intensive care unit (ICU) patients in the post-operative setting [2], and in patients with burns [3] or suffering from cerebral lesions [4]. In patients admitted to the ICU with

\section{Biomed Central}


community-acquired infectious meningitis, prompt and adequate anti-infective treatment is mandatory and high drug dosage administration is advocated [5] to achieve effective anti-infective agent concentrations in the cerebral spinal fluid (CSF). Some of these anti-infective agents undergo kidney clearance. However, the presence of high $\mathrm{CrCl}$ in this group of patients is particularly interesting because it may allow the physician to adopt specific anti-infective dosing strategies and thereby avoid treatment failure and drug-induced resistance [6]. The major aim of the study was to record the rate of high $\mathrm{CrCl}$, calculated by 24-hr UV/P creatinine, in patients admitted to the ICU with community-acquired infectious meningitis. The secondary aim was to assess the accuracy of Cockcroft-Gault formula and the simplified MDRD equation in identifying high $\mathrm{CrCl}$.

\section{Methods}

\section{Study patients}

We reviewed the charts of all consecutive patients older than 18 years admitted between January 2006 and December 2009 to the 9-bed medical ICU of the University Hospital of Clermont-Ferrand (France) for community-acquired acute infectious meningitis. A computerized search tool was used to identify patients from the hospital discharge diagnostic database. Meningitis was defined by CSF pleocytosis $>7$ white blood cells $\times 10^{6} / \mathrm{L}$, as proposed by other investigators [7]. Patients with meningitis due to a documented non-infectious cause or that had occurred during hospitalization or within one week after discharge were excluded. Patient characteristics, clinical features, results of investigations, treatment, and outcome were extracted from medical records. The item "diabetes" corresponded to patients receiving a specific medication for diabetes before hospital admission. The Simplified Acute Physiology Score (SAPS) II score and the Sequential Organ Failure Assessment (SOFA) score on the admission-day were calculated from the charts.

\section{Assessment of creatinine clearance}

In our ICU, the patient's weight, 24-hour urine output, serum and urine creatinine levels are daily measured as standard practice. All serum creatinine samples are measured by the hospital biochemistry laboratory, using a compensated Jaffe method (Modular P, Roche Diagnostics GmbH, Mannheim, Germany). No change in clinical practice was made during the study period. $\mathrm{CrCl}$ was determined daily during the first 7 days of ICU stay by one measured method, 24-hr-UV/P creatinine, and two estimated methods, Cockcroft-Gault formula and the simplified MDRD equation (Additional file 1: Table S1) [1]. The $\mathrm{CrCl}$ measured by 24-hr UV/P creatinine and estimated by Cockcroft's equation was normalized by body surface area, as recommended by KDOQI guidelines [1]. The height and weight used for calculation of body surface area were measured on ICU admission. The patients' height and weight were measured in a supine position with a tape measure and a Hill-Rom bed (Medicraft, Marrickville NSW, Australia), respectively. High $\mathrm{CrCl}$ was defined as $\mathrm{CrCl}>140 \mathrm{ml} / \mathrm{min} / 1.73 \mathrm{~m}^{2}$ by 24-hr-UV/P creatinine.

\section{Statistical analysis}

High $\mathrm{CrCl}$ was expressed as incidence, in which the numerator is the number of patients with at least one measurement of high $\mathrm{CrCl}$ and the denominator the overall number of patients. The percentage of days with a high $\mathrm{CrCl}$ during the first 7 days of ICU stay was expressed as duration ratio, in which the numerator is the total number of days with high $\mathrm{CrCl}$ and the denominator the total number of ICU days of the overall population. High $\mathrm{CrCl}$ incidence and duration ratio were therefore expressed as a percentage. Continuous variables, presented as mean $\pm \mathrm{SD}$ or as median (IQR), were compared by Mann-Whitney $U$ test. Categorical variables were compared by Fisher's exact test.

For comparisons between measurements methods, we built a Bland-Altman plot between differences and averages seeking possible biases and outliers. The diagnostic accuracy of Cockcroft-Gault formula and the simplified MDRD equation in predicting high $\mathrm{CrCl}$ was then assessed by measuring the area under the receiver operating characteristic (ROC) curves. Each measure was treated as an independent event. The areas under the ROC curves were compared by the Wilcoxon rank test. The best threshold with their corresponding likelihood ratios (negative and positive) was defined by Youden's index. Statistical tests were performed with the SAS program except for the AUC, which was assessed by Medcalc. A value of $\mathrm{p}<0.05$ was considered to be significant.

\section{Results}

During the study period, 1266 patients were admitted to the ICU. Of these, 32 had community-acquired acute infectious meningitis. No cases were excluded because of missing data. The characteristics of the patients and the causative organisms of meningitis are shown in Tables 1 and 2 , respectively. In 18 patients bacterial or fungal meningitis was diagnosed by a positive CSF culture, and in 2 patients viral meningitis was diagnosed by a positive CSF viral polymerase chain reaction test result. In 12 patients the diagnosis of community-acquired acute infectious meningitis was considered in spite of the absence of a causative organism. Of these, 7 were receiving antibiotics prior to lumbar puncture. In the 12 patients, the mean CSF glucose level, protein level and white 
Table 1 Characteristics of the patients

\begin{tabular}{|c|c|}
\hline Characteristics & $\mathrm{N}=32$ \\
\hline Gender ratio (men/women) & $15 / 17$ \\
\hline Age, $y \mathrm{ys}^{\mathrm{a}, \mathrm{b}}$ & $54 \pm 16$ \\
\hline Weight, kg a,b & $71 \pm 25$ \\
\hline Height, $\mathrm{cm}^{\mathrm{a}, \mathrm{b}}$ & $166 \pm 11$ \\
\hline Body surface area, $m^{2}, a, b$ & $1.77 \pm 0.27$ \\
\hline Diabetes, $\mathrm{n}(\%)^{\mathrm{b}}$ & $6(19)$ \\
\hline SAPSII, pts ${ }^{\mathrm{a}, \mathrm{b}}$ & $46 \pm 19$ \\
\hline SOFA, pts $s^{a, b}$ & $7 \pm 4$ \\
\hline Neurologic SOFA, pts ${ }^{a, b}$ & $2 \pm 1$ \\
\hline Mechanical ventilation, $\mathrm{n}(\%)^{c}$ & $22(69)$ \\
\hline Vasopressive drug, $\mathrm{n}(\%)^{\mathrm{c}}$ & $13(41)$ \\
\hline Renal replacement therapy, $\mathrm{n}(\%)^{\mathrm{c}}$ & $3(9)$ \\
\hline ICU length of stay, days ${ }^{\text {d }}$ & $13(8-19)$ \\
\hline ICU mortality, n (\%) & $4(12)$ \\
\hline
\end{tabular}

cells count was $5.0 \pm 2.4 \mathrm{mmol} / \mathrm{L}, 1.1 \pm 1.4 \mathrm{~g} / \mathrm{L}$, and $47 \pm 53 \times 10^{6} / \mathrm{L}$, respectively.

The incidence of high $\mathrm{CrCl}$ was $47 \%$ (15/32) during the 7 -day study period, and the duration ratio was $26 \%$. On ICU admission, the frequency of high $\mathrm{CrCl}$ was $25 \%(8 / 32)$. The daily frequency of high $\mathrm{CrCl}$ was unchanged throughout the first 7 days of ICU stay, $(P=0.60)$ (Figure 1). Except for SAPS II on admission, there were no differences in the characteristics of the population upon admission and during ICU stay irrespective of the presence or absence of high $\mathrm{CrCl}$ (Additional file 2: Tables S2 and Additional file 3: Table S3).

For the diagnosis of high $\mathrm{CrCl}$, the area under the ROC curves of Cockcroft-Gault formula was $0.90 \pm 0.03$ and the simplified MDRD equation was $0.88 \pm 0.03$. Between Cockcroft-Gault formula and the simplified

Table 2 Causative organisms of meningitis

\begin{tabular}{ll}
\hline & $\mathbf{N}=\mathbf{3 2}$ \\
\hline Bacteria & 9 \\
Streptococcus pneumoniae, $\mathrm{n}$ & 3 \\
Other strepotococci, $\mathrm{n}$ & 2 \\
Staphylococcus aureus, $\mathrm{n}$ & 1 \\
Mycobacterium Tuberculosis, $\mathrm{n}$ & 1 \\
Escherichia coli, $\mathrm{n}$ & \\
Virus & 1 \\
Herpes virus type 6, n & 1 \\
Cytomegalovirus, $\mathrm{n}$ & \\
Parasite & 2 \\
Cryptococcus neoformans, $\mathrm{n}$ & 12 \\
Indeterminate, $\mathrm{n}$ & \\
\hline
\end{tabular}

MDRD equation, there was no difference in the diagnostic accuracy identifying high $\mathrm{CrCl}(\mathrm{P}=0.30)$. For Cockcroft-Gault formula, the best threshold was $101 \mathrm{ml} / \mathrm{min} / 1.73 \mathrm{~m}^{2}$, corresponding to a sensitivity of $96 \%$ and a specificity of $75 \%$. For the simplified MDRD equation, the best threshold was $108 \mathrm{ml} / \mathrm{min} / 1.73 \mathrm{~m}^{2}$ with a sensitivity of $91 \%$ and a specificity of $80 \%$. Bias, as illustrated by the mean difference in the Bland and Altman analysis between 24-hr-UV/P creatinine and Cockcroft-Gault formula and between 24-hr-UV/P creatinine and the simplified MDRD equation was 0.9 and $-3.1 \mathrm{ml} / \mathrm{min} / 1.73 \mathrm{~m}^{2}$ respectively. The differences, as illustrated by the $\pm 95 \%$ fluctuation interval in the Bland-Altman graphs, between 24-hr-UV/P creatinine and Cockcroft-Gault formula and between 24-hr-UV/P creatinine and the simplified MDRD equation were -99.7 to $101.4 \mathrm{ml} / \mathrm{min} / 1.73 \mathrm{~m}^{2}$ and -113.1 to $106.9 \mathrm{ml} / \mathrm{min} /$ $1.73 \mathrm{~m}^{2}$, respectively (Additional file 4: Figures S1A-B). Four of the 44 measurements with high $\mathrm{CrCl}$ had a value of simplified MDRD equation under the threshold of $108 \mathrm{ml} / \mathrm{min} / 1.73 \mathrm{~m}^{2}$ from ROC curve analysis (Figure 2). The likelihood ratio of a negative result was 0.11, meaning that the odds of high $\mathrm{CrCl}$ is 10 times smaller when the value of simplified MDRD equation is under the threshold of $108 \mathrm{ml} / \mathrm{min} / 1.73 \mathrm{~m}^{2}$.

Of the 44 measurements with high $\mathrm{CrCl}, 2$ had a value of Cockcroft-Gault formula under the threshold of $101 \mathrm{ml} / \mathrm{min} / 1.73 \mathrm{~m}^{2}$ from ROC curve analysis (Figure 3). The likelihood ratio of a negative result was 0.06 , meaning that the odds of high $\mathrm{CrCl}$ is more than 10 times smaller when the value of CockcroftGault formula is under the threshold of $101 \mathrm{ml} / \mathrm{min} /$ $1.73 \mathrm{~m}^{2}$. There was no difference in the $15 \%$ and $30 \%$ accuracy between Cockcroft-Gault formula and the simplified MDRD equation for diagnosing high $\mathrm{CrCl}, 36 \%$ vs $20 \%(\mathrm{P}=0.17)$ and $68 \%$ vs $52 \%$, $(P=0.19)$, respectively.

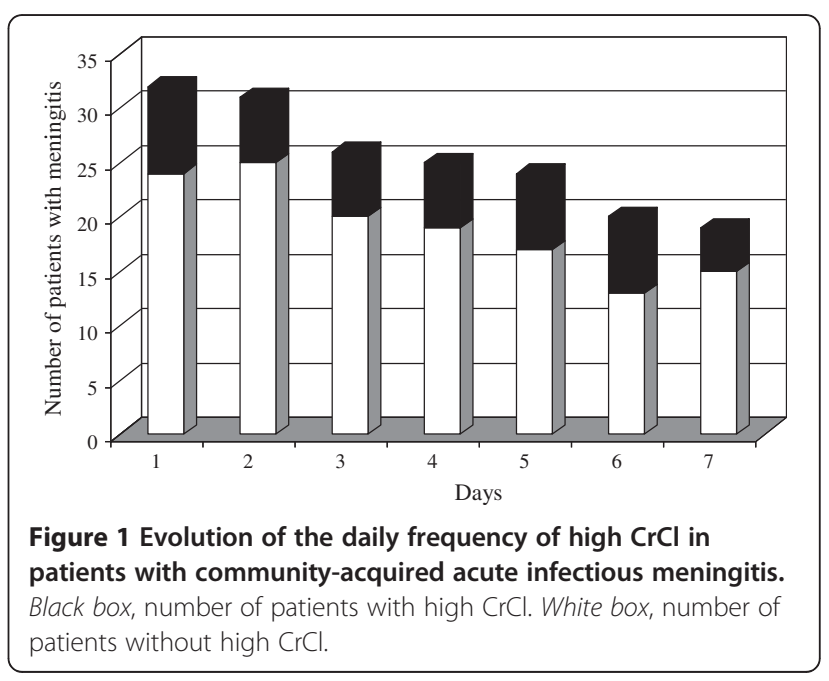




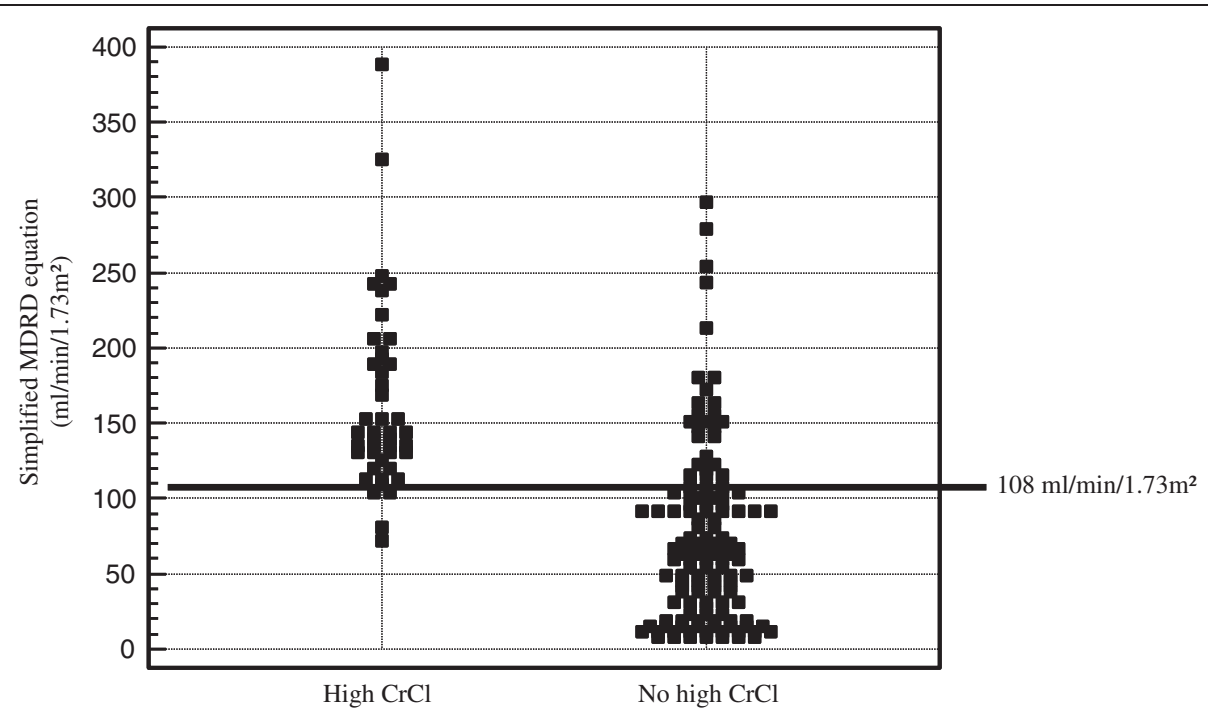

Figure 2 Distribution of creatinine clearance values performed with simplified MDRD equation according of the diagnosis of high $\mathrm{CrCl}$.

\section{Discussion}

Our study showed that high $\mathrm{CrCl}$ is often seen on admission in ICU patients with community-acquired acute infectious meningitis. It can persist for several days and be predicted by the estimated methods.

$\mathrm{CrCl}$ is classically screened for GFR despite limitations. Creatinine is metabolised and secreted by the renal tubule, and hence $\mathrm{CrCl}$ both overestimates the GFR and delays the diagnosis of acute kidney injury. Inulin clearance is the gold standard test for accurately measuring GFR. However it is complex to perform, highly expensive, and cannot therefore be routinely used in ICU patients. Iohexol clearance is an alternative to estimating GFR. However, the use of iodine in the test probably precludes its sequential and repeated use in patients and in healthy volunteers. In clinical practice, despite its limitations, $\mathrm{CrCl}$ is currently used to estimate GFR because it is inexpensive, harmless, and easy to perform, particularly in ICU patients. Moreover, it is now well established that small plasma creatinine variations are independently associated with poor prognosis in ICU patients [8], reinforcing the widespread measurement of plasma creatinine for the diagnosis and follow up of kidney function in these patients.

There is no consensus on what constitute normal GFR values, but most authors consider them to range between 90 and $130 \mathrm{ml} / \mathrm{min} / 1.73 \mathrm{~m}^{2}$ [9]. Similarly, the normal values of $\mathrm{CrCl}$ are not agreed upon and most

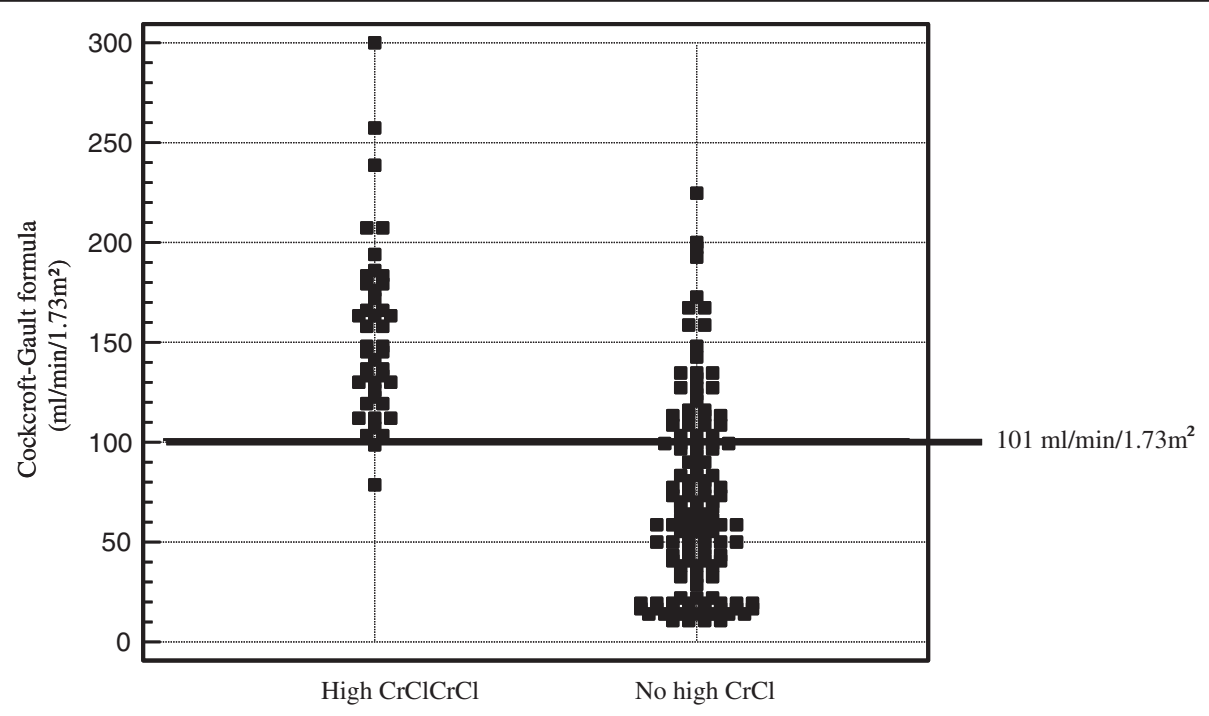

Figure 3 Distribution of creatinine clearance values performed with Cockcroft-Gault formula according of the diagnosis of high $\mathrm{CrCl}$. 
authors extrapolate them from those defined for GFR. Several threshold values have been used to define high $\mathrm{CrCl}$, ranging from $120 \mathrm{ml} / \mathrm{min} / 1.73 \mathrm{~m}^{2}$ to $150 \mathrm{ml} /$ $\min / 1.73 \mathrm{~m}^{2}$ for women and $160 \mathrm{ml} / \mathrm{min} / 1.73 \mathrm{~m}^{2}$ for men [10-13]. In light of all these factors, we chose a $140 \mathrm{ml} / \mathrm{min} / 1.73 \mathrm{~m}^{2}$ threshold to define high $\mathrm{CrCl}$. This probably allows a greater specificity in the diagnosis of high $\mathrm{CrCl}$ than in most studies. We made no distinction between male and female patients since gender entails no difference in treatment, in particular with regard to dosage. Cockcroft-Gault formula and simplified MDRD equation are commonly used to determine $\mathrm{CrCl}$ because diuresis quantification and urinary creatinine measurement are not necessary in the equations. Hence, estimation of $\mathrm{CrCl}$ by these two methods is simpler than calculation by $24-\mathrm{hr} \mathrm{UV} / \mathrm{P}$ creatinine. $\mathrm{CrCl}$ as estimated from equations has been recommended for dosage adjustment in patients with reduced kidney function receiving antibiotics with renal elimination. However, no consensus firmly states which methods must be used in ICU patients to determine $\mathrm{CrCl}$. In our study we defined high $\mathrm{CrCl}$ as clearance above $140 \mathrm{ml} / \mathrm{min} / 1.73 \mathrm{~m}^{2}$ by 24-hr UV/P creatinine. As reported elsewhere, our results demonstrate that $\mathrm{CrCl}$ calculated with the 24-hr UV/P creatinine and estimated from equations may yield different results $[3,12,14]$. Baptista et al. reported that in patients with augmented $\mathrm{CrCl}$, the estimated methods of $\mathrm{CrCl}$ significantly under-estimate the measured value of the calculated method [12]. Our findings are in agreement with previously published data and suggest that the estimated methods of $\mathrm{CrCl}$ could be used as a screening tool to diagnose high $\mathrm{CrCl}$ with a $101 \mathrm{ml} / \mathrm{min} /$ $1.73 \mathrm{~m}^{2}$ threshold for Cockcroft-Gault formula and a $108 \mathrm{ml} / \mathrm{min} / 1.73 \mathrm{~m}^{2}$ threshold for simplified MDRD equation. The simplified MDRD equation and the Cockcroft-Gault formula make it possible to rule out a high $\mathrm{CrCl}$ when their values are under their respective thresholds.

There is a paucity of information in the literature relating to the characteristics of high $\mathrm{CrCl}$ in ICU patients. The incidence of high $\mathrm{CrCl}$ in a general population of ICU patients can vary between $18 \%$ [11] and $41 \%$ [12]. The main factors associated with high $\mathrm{CrCl}$ in these studies are young age, greater body surface area, higher diastolic blood pressure, diuresis levels, lower APACHE III scores at admission and multiple trauma $[10,11]$. In a small sample of patients with head trauma, the incidence of high $\mathrm{CrCl}$ was $85 \%$ [13]. In addition, some studies that did not specifically deal with high $\mathrm{CrCl}$ but either with the assessment of renal function in particular ICU patient groups (burns, trauma, brain injury, surgery) $[2-4,10]$, or with the pharmacokinetic and pharmacodynamic properties of antibiotics [15-18], recorded an incidence of high $\mathrm{CrCl}$ ranging from $3 \%$ to $50 \%$ and values between 130 and $200 \mathrm{ml} / \mathrm{min} / 1,73 \mathrm{~m}^{2}$.

Little is known about the pathological mechanisms of high $\mathrm{CrCl}$ in ICU patients. The condition has been reported during pregnancy, following nephrectomy, at the onset of diabetic kidney disease, in obesity, in sickle cell anaemia [19] and in children with haemopathy [20]. It has been suggested that high $\mathrm{CrCl}$ occurs as a result of glomerular hyperperfusion [21]. Experimental studies have shown that high $\mathrm{CrCl}$ is observed during the initial hyperkinetic phase of sepsis [22,23]. However, this hypothesis cannot account for all cases of high $\mathrm{CrCl}$ in acute or chronic situations. Another suggested explanation for high $\mathrm{CrCl}$ when it is detected at the onset of diabetic kidney disease is that hyperglycaemia stimulates the re-absorption of sodium in the proximal tubule thereby decreasing its supply to the distal tubule. This would set off tubuloglomerular feedback in the macula densa and result in dilatation of the afferent arteriole and an increase in GFR [24]. A third explanation, in particular in children with malignancies and in obese patients is that high $\mathrm{CrCl}$ is due to the kidney adjusting to the high protein load caused by large tumours [20] or to the hypermetabolism brought on by obesity [25]. No single hypothesis of the above three seems to explain the high $\mathrm{CrCl}$ observed in our study, and it is likely that several mechanisms occur in combination.

In drugs with kidney clearance, a decrease or increase in normal GFR can have a major impact on its plasma concentration. Lowered GFR impairs elimination of the drug and can lead to excessively high concentrations if the dosage is not decreased or if the intervals between doses are not lengthened. Drug overdosage can have serious side effects resulting in increased morbidity $[15,26]$ and for this reason there are dosage guidelines to be followed in the event of a decrease in GFR. Conversely, high GFR can lead to greater concentrations of the drug being eliminated with the possible risk of insufficient dosage and hence treatment failure or, in the case of antibiotics, the emergence of resistant bacteria. There are currently no guidelines for adjusting drug dosage when GFR is high. Our study is not able to assess the pharmacokinetic or pharmacodynamic effects of a drug during high $\mathrm{CrCl}$. Assessments of these effects elsewhere have shown that there is a close connection between the plasma concentration of a drug and $\mathrm{CrCl}$ and that, for example, high $\mathrm{CrCl}$ is associated with low plasma concentrations of the drug [15,16,27-29]. This suggests that high $\mathrm{CrCl}$ could lower drug concentration to a level that renders it therapeutically ineffective, despite a seemingly appropriate dosage. No study has shown a causal relation between high $\mathrm{CrCl}$ and failure of drug treatment. Our study shows that high $\mathrm{CrCl}$ can persist for several days. It is possible that when high $\mathrm{CrCl}$ lasts only a few 
hours it has little impact clinically whereas a longer period of high $\mathrm{CrCl}$ would probably require daily dosage adjustment. It would be interesting to perform a daily monitoring of the presence and intensity of high $\mathrm{CrCl}$ in patients taking drugs excreted by the kidneys.

Our study has several limitations. First, it was retrospective and therefore we cannot rule out the possibility that certain eligible patients were excluded because of an oversight in the computer rating of diagnosis of meningitis. However, the main outcome criterion, the incidence of high $\mathrm{CrCl}$, did not influence the selection of the patients recruited. Second, it was a monocentric study including only ICU patients admitted for meningitis, and so extrapolating the results to a general ICU population remains speculative. The study was focused on patients with meningitis, since in this clinical situation, prompt antiinfectious treatment with both adequate agent and dosage is mandatory for preventing poor outcome. High $\mathrm{CrCl}$ may impact the pharmacokinetics of the drugs resulting in therapeutic failure due to low drug concentration despite an apparent appropriate drug dosage. Third, the diagnosis of meningitis was based on CSF white cell count, and therefore may have been overestimated. However, this diagnostic criterion is classically used in studies on meningitis in ICU patients and the magnitude of the results would not have been different if we had limited the study to patients with meningitis defined by a CSF culture yielding a microorganism. Fourth, $\mathrm{CrCl}$ rate can be affected by certain drugs, such as cimetidine [30] and trimethoprim [31], that stimulate tubular secretion of creatinine. No such drugs were administered in our cohort.

\section{Conclusions}

Half of ICU patients with community-acquired acute infectious meningitis have high $\mathrm{CrCl}$, which, in many cases, may persist for several days. High $\mathrm{CrCl}$ can be ruled out when a value of the Cockcroft-Gault formula is under a threshold of $101 \mathrm{ml} / \mathrm{min} / 1.73 \mathrm{~m}^{2}$ or when a value of the simplified MDRD equation formula is under a threshold of $108 \mathrm{ml} / \mathrm{min} / 1.73 \mathrm{~m}^{2}$. There is a need to assess the clinical impact of high $\mathrm{CrCl}$ in $\mathrm{ICU}$ patients.

\section{Additional files}

Additional file 1: Table S1. Formula used to determine creatinine clearance and body surface area.

Additional file 2: Table S2. Demographic data of patients suffering from meningitis with or without high $\mathrm{CrCl}$.

Additional file 3: Table S3. Causative organisms of meningitis in patients with or without high $\mathrm{CrCl}$.
Additional file 4: Figure S1. Bland and Altman analysis of 24-hr-UV/P creatinine and the Cockcroft-Gault formula (A) and of 24-hr-UV/P creatinine and the simplified MDRD equation (B).

\section{Abbreviations}

GFR: Glomerular filtration rate; $\mathrm{CrCl}$ : Creatinine clearance; MDRD: Modification of diet in renal disease; ICU: Intensive care unit; CSF: Cerebral spinal fluid; SAPS: Simplified Acute Physiology Score; SOFA: Sequential Organ Failure Assessment; ROC: Receiver operating characteristic; AUC: Area under the ROC curve; KDOQI: Kidney disease outcomes quality initiative; APACHE: Acute physiology and chronic health evaluation.

\section{Competing interests}

The authors declare that they have no competing interests.

\section{Authors' contributions}

TNP collected data. LO performed the statistical analysis. AAH, VT and AEH reviewed the intellectual content. AL and BS conceived of the study, drafted the manuscript and performed the statistical analysis. All authors read and approved the final manuscript.

\section{Acknowledgements}

We are indebted to Mr. Jeffrey Watts for assistance in the preparation of the manuscript.

\section{Author details}

${ }^{1}$ Departments of Intensive Care Unit and Nephrology, University hospital of Clermont-Ferrand, Clermont-Ferrand, France. ${ }^{2}$ Univ Clermont 1, UFR Médecine, Clermont-Ferrand F-63001, France. ${ }^{3}$ Departments of Biostatistics, University hospital of Clermont-Ferrand, Clermont-Ferrand, France.

Received: 29 May 2012 Accepted: 22 September 2012

Published: 27 September 2012

\section{References}

1. KDOQI Clinical Practice Guidelines and Clinical Practice Recommendations for 2006 Updates: Hemodialysis Adequacy, Peritoneal Dialysis Adequacy and Vascular Access. Am J Kidney Dis 2006, 48(S1):S1-S322.

2. Brown R, Babcock R, Talbert J, Gruenberg J, Czurak C, Campbell M: Renal function in critically ill postoperative patients: sequential assessment of creatinine osmolar and free water clearance. Crit Care Med 1980, 8(2):68-72.

3. Conil JM, Georges B, Fourcade O, Seguin T, Lavit M, Samii K, Houin G, Tack I, Saivin S: Assessment of renal function in clinical practice at the bedside of burn patients. Br J Clin Pharmacol 2007, 63(5):583-594.

4. Albanese J, Leone M, Garnier F, Bourgoin A, Antonini F, Martin C: Renal effects of norepinephrine in septic and nonseptic patients. Chest 2004, 126(2):534-539.

5. Proulx N, Frechette D, Toye B, Chan J, Kravcik S: Delays in the administration of antibiotics are associated with mortality from adult acute bacterial meningitis. QJM 2005, 98(4):291-298.

6. Udy AA, Roberts JA, Lipman J: Implications of augmented renal clearance in critically ill patients. Nat Rev Nephrol 2011, 7(9):539-543.

7. Brivet FG, Ducuing S, Jacobs F, Chary I, Pompier R, Prat D, Grigoriu BD, Nordmann P: Accuracy of clinical presentation for differentiating bacterial from viral meningitis in adults: a multivariate approach. Intensive Care Med 2005, 31(12):1654-1660.

8. Lafrance JP, Miller DR: Acute kidney injury associates with increased longterm mortality. J Am Soc Nephrol 2010, 21(2):345-352.

9. Stevens LA, Coresh J, Greene T, Levey AS: Assessing kidney functionmeasured and estimated glomerular filtration rate. N Engl J Med 2006, 354(23):2473-2483.

10. Minville V, Asehnoune K, Ruiz S, Breden A, Georges B, Seguin T, Tack I, Jaafar A, Saivin S, Fourcade O, et al: Increased creatinine clearance in polytrauma patients with normal serum creatinine: a retrospective observational study. Crit Care 2011, 15(1):R49.

11. Fuster-Lluch O, Geronimo-Pardo M, Peyro-Garcia R, Lizan-Garcia M: Glomerular hyperfiltration and albuminuria in critically ill patients. Anaesth Intensive Care 2008, 36(5):674-680. 
12. Baptista JP, Udy AA, Sousa E, Pimentel J, Wang L, Roberts JA, Lipman J: A comparison of estimates of glomerular filtration in critically ill patients with augmented renal clearance. Crit Care 2011, 15(3):R139.

13. Udy A, Boots R, Senthuran S, Stuart J, Deans R, Lassig-Smith M, Lipman J: Augmented creatinine clearance in traumatic brain injury. Anesth Analg 2010, 111(6):1505-1510.

14. Hoste EA, Damen J, Vanholder RC, Lameire NH, Delanghe JR, Van den Hauwe K, Colardyn FA: Assessment of renal function in recently admitted critically ill patients with normal serum creatinine. Nephrol Dial Transplant 2005, 20(4):747-753.

15. Conil JM, Georges B, Mimoz O, Dieye E, Ruiz S, Cougot P, Samii K, Houin G, Saivin S: Influence of renal function on trough serum concentrations of piperacillin in intensive care unit patients. Intensive Care Med 2006, 32(12):2063-2066.

16. Georges B, Conil JM, Seguin T, Ruiz S, Minville V, Cougot P, Decun JF, Gonzalez H, Houin G, Fourcade O, et al: Population pharmacokinetics of ceftazidime in intensive care unit patients: influence of glomerular filtration rate, mechanical ventilation, and reason for admission. Antimicrob Agents Chemother 2009, 53(10):4483-4489.

17. Pea F, Viale P, Candoni A, Pavan F, Pagani L, Damiani D, Casini M, Furlanut M: Teicoplanin in patients with acute leukaemia and febrile neutropenia: a special population benefiting from higher dosages. Clin Pharmacokinet 2004, 43(6):405-415.

18. de Gatta MM F, Mendez ME, Romano S, Calvo MV, Dominguez-Gil A, Lanao JM: Pharmacokinetics of amikacin in intensive care unit patients. J Clin Pharm Ther 1996, 21(6):417-421.

19. Haymann JP, Stankovic K, Levy P, Avellino V, Tharaux PL, Letavernier E, Grateau G, Baud L, Girot R, Lionnet F: Glomerular hyperfiltration in adult sickle cell anemia: a frequent hemolysis associated feature. Clin J Am Soc Nephrol 2008, 5(5):756-761.

20. Hjorth L, Wiebe T, Karpman D: Hyperfiltration evaluated by glomerular filtration rate at diagnosis in children with cancer. Pediatr Blood Cancer 2011, 56(5):762-766.

21. Praga M: Synergy of low nephron number and obesity: a new focus on hyperfiltration nephropathy. Nephrol Dial Transplant 2005, 20(12):2594-2597.

22. Di Giantomasso D, May CN, Bellomo R: Norepinephrine and vital organ blood flow. Intensive Care Med 2002, 28(12):1804-1809.

23. Wan L, Bellomo R, May CN: The effects of normal and hypertonic saline on regional blood flow and oxygen delivery. Anesth Analg 2007, 105(1):141-147.

24. Thomson SC, Vallon V, Blantz RC: Kidney function in early diabetes: the tubular hypothesis of glomerular filtration. Am J Physiol Renal Physiol 2004, 286(1):F8-F15.

25. Griffin KA, Kramer H, Bidani AK: Adverse renal consequences of obesity. Am J Physiol Renal Physiol 2008, 294(4):F685-F696.

26. Pea F, Pavan F, Furlanut M: Clinical relevance of pharmacokinetics and pharmacodynamics in cardiac critical care patients. Clin Pharmacokinet 2008, 47(7):449-462.

27. Goncalves-Pereira J, Povoa P: Antibiotics in critically ill patients: a systematic review of the pharmacokinetics of beta-lactams. Crit Care 2011, 15(5):R206.

28. Udy AA, Varghese JM, Altukroni M, Briscoe S, McWhinney B, Ungerer J, Lipman J, Roberts JA: Sub-therapeutic initial beta-lactam concentrations in select critically ill patients: association between augmented renal clearance and low trough drug concentrations. Chest 2011, 142(1):30-39.

29. Baptista JP, Sousa E, Martins PJ, Pimentel JM: Augmented renal clearance in septic patients and implications for vancomycin optimisation. Int J Antimicrob Agents 2012, 39(5):420-423.

30. Hilbrands LB, Artz MA, Wetzels JF, Koene RA: Cimetidine improves the reliability of creatinine as a marker of glomerular filtration. Kidney Int 1991, 40(6):1171-1176.

31. Berg KJ, Gjellestad A, Nordby G, Rootwelt K, Djoseland O, Fauchald P, Mehl A, Narverud J, Talseth T: Renal effects of trimethoprim in ciclosporin- and azathioprine-treated kidney-allografted patients. Nephron 1989, 53(3):218-222

\section{doi:10.1186/1471-2369-13-124}

Cite this article as: Lautrette et al:: High creatinine clearance in critically ill patients with community-acquired acute infectious meningitis. BMC Nephrology 2012 13:124.

\section{Submit your next manuscript to BioMed Central and take full advantage of:}

- Convenient online submission

- Thorough peer review

- No space constraints or color figure charges

- Immediate publication on acceptance

- Inclusion in PubMed, CAS, Scopus and Google Scholar

- Research which is freely available for redistribution 